\title{
Coagulation Factor Activity and Hemostatic Markers of Endothelial Dysfunction in Patients with Peripheral Arterial Disease
}

\author{
Roman E. Kalinin ${ }^{1}$, lgor A. Suchkov ${ }^{1}$, Nina D. Mzhavanadze ${ }^{1}$, Olga N. Zhurina $^{2}$, \\ Emma A. Klimentova ${ }^{1}$, and Vladislav O. Povarov ${ }^{1}$ \\ ${ }^{1}$ Department of Cardiovascular, Endovascular, Operative Surgery, and Topographic Anatomy, Ryazan State Medical University, Ryazan, \\ ${ }^{2}$ Clinical Research Center for Hematology, Oncology and Immunology, Ryazan State Medical University, Ryazan, Russia
}

Purpose: We aimed to evaluate the impact of intrinsic coagulation factors and hemostatic markers of endothelial dysfunction on complications in patients with atherosclerotic peripheral arterial disease (PAD).

Materials and Methods: This prospective study enrolled 120 PAD patients at Fontaine stages $2 \mathrm{~b}$ to 3 who underwent open surgical, endovascular, or conservative treatment. Coagulation factors (FVIII, FIX, and FXI) and endothelial hemostatic markers, including von Willebrand factor (vWF) activity and level, soluble endothelial protein $\mathrm{C}$ receptor, and plasminogen activator inhibitor-1 (PAl-1) levels, were assessed.

Results: At 3 months after open bypass grafting, activity of FVIII significantly increased from a median of $175 \%$ to $233 \%(\mathrm{P}<0.001)$. At 3 months after endovascular treatment, the activities of FVIII, FIX, and FXI significantly increased from medians of $157 \%, 180 \%$, and $156 \%$ to $184 \%, 218 \%$, and $181 \%$, respectively $(\mathrm{P}<0.05)$. Six patients with increased FVIIl activity developed bypass graft thrombosis. Four patients in the endovascular group and three patients in the conservative treatment group with increased activity of VWF developed myocardial infarction $(\mathrm{P}=0.049)$. The subjects who developed restenosis had increased vWF activity $(\mathrm{P}=0.023)$ and decreased nitric oxide metabolite levels $(\mathrm{P}=0.003)$. Three subjects who received conservative treatment and developed $\mathrm{PAD}$ progression at 12 months had increased PAl-1 activity ( $\mathrm{P}=0.028)$.

Conclusion: Patients with advanced PAD had a hypercoagulable status, and performance of open or endovascular revascularization was associated with further hypercoagulability. Increased activity of coagulation factors and altered levels of hemostatic markers of endothelial dysfunction were associated with PAD complications such as graft thrombosis, myocardial infarction, disease progression, and restenosis.

Key Words: Hemostasis, Vascular endothelium, Thrombosis, Endovascular procedures, Peripheral arterial disease
Received February 3, 2021

Revised June 14, 2021

Accepted July 5, 2021

Published on August 5, 2021

Corresponding author: Nina D. Mzhavanadze

Department of Cardiovascular, Endovascular, Operative Surgery, and Topographic Anatomy, Ryazan State Medical University, Vysokovoltnaya 9, Ryazan 390026, Russia

Tel: 79156061756

Fax: 74912971808

E-mail: nina_mzhavanadze@mail.ru https://orcid.org/0000-0001-5437-1112

This is an Open Access article distributed under the terms of the Creative Commons Attribution Non-Commercial License (http://creativecommons.org/licenses/by-nc/4.0) which permits unrestricted non-commercial use, distribution, and reproduction in any medium, provided the original work is properly cited.

Cite this article; Vasc Specialist Int 2021. https://doi.org/10.5758/vsi.210010 


\section{INTRODUCTION}

Post-procedural patency rates of peripheral vessels after reconstruction in patients with atherosclerotic peripheral arterial disease (PAD) may vary due to the development of thrombotic complications, restenosis, and disease progression. While peripheral procedures using autologous vein grafts have rather satisfactory results, prosthetic grafts tend to occlude within the first year for up to $20 \%$ of aboveknee procedures and 75\% of below-knee interventions [1]. Thrombosis rates reach $12.5 \%$ within one year after peripheral procedures involving endovascular stents [2].

Shear stress, coagulation factors, and hemostatic molecules produced by the endothelium, including soluble endothelial protein $\mathrm{C}$ receptor (sEPCR), von Willebrand factor (vWF), plasminogen activator inhibitor-1 (PAl-1), adhesion molecules, pro-inflammatory cytokines, and chemokines play important biological roles in hemostasis and vascular remodeling [3,4]. Nowadays, the intrinsic pathway is regarded as a key player in thrombogenesis, immunity, and inflammation $[5,6]$. The main factors of the intrinsic coagulation pathway are factors VIII, IX, Xl, and XIl. Along with these four factors, vWF, an adhesive glycoprotein, binds to factor VIII and protects it from inactivation through proteolysis by activated protein C, which binds to the SEPCR and is then activated by the thrombin-thrombomodulin complex [7]. Factor VIII binds to VWF; the latter has long been regarded as an important marker of endothelial dysfunction while the role and origin of its binding agent, factor VIII, remain understudied. It has been recently discovered that factor VIII is produced not only in sinusoid endothelial liver cells but also in extra-hepatic endothelium [8]. Coagulation proteases not only regulate hemostasis and thrombosis, but also contribute to hemostatic cellular responses. Thrombin affects the detachment of factor VIII from the VWF complex and thus activates factor Xla [9]. Additionally, factor IXa is formed under the action of factor Xla, and a tenase complex is formed by activated factors VIIla and IXa with calcium ions on the surface of platelets [10]. Kotschy et al. [11] investigated the influence of different hemostatic parameters on restenosis and thrombosis and concluded that the main association was with tissue factor (TF) level from the extrinsic pathway; by binding factor Vlla, the TF-Vlla complex activates factors $\mathrm{IX}$ and $\mathrm{X}$, which leads to fibrin formation [11]. Srámek et al. [12] found that decreased concentrations of factors VIII and IX were associated with 80\% reduced mortality due to coronary artery disease. Increased activity of factor $\mathrm{XI}$ was associated with a higher risk of ischemic stroke. Factor XII becomes active on a charged surface via contact activation, which then activates both factors IX and XI. However, factor XII was not associated with myocardial infarction or ischemic stroke risk [13].

Assessment of the pathogenesis of thrombotic complications in patients with PAD may provide insight into the future possible application of alternative antithrombotic therapies. We aimed to evaluate the impact of intrinsic coagulation factor activities and hemostatic markers of endothelial dysfunction on thrombotic complications in patients with PAD.

\section{MATERIALS AND METHODS}

The study was performed in the Department of Cardiovascular, Endovascular, Operative Surgery, and Topographic Anatomy at Ryazan State Medical University, Russia, from 2017 to 2019. This prospective study enrolled 120 patients with chronic lower limb ischemia due to PAD in Fontaine stages $2 \mathrm{~b}$ to 3 (Rutherford category $3-4$ ). The inclusion criteria were as follows: (1) males or females aged $\geq 40$ years old and (2) presence of PAD. The exclusion criteria were as follows: (1) males or females aged $<40$ years old; (2) has chronic lower limb ischemia of a different etiology (e.g., Buerger disease, aortoarteritis, etc.); (3) has active cancer or had cancer with a remission period of $<5$ years; (4) has decompensated diabetes mellitus; and (5) pregnant and/or breastfeeding.

All participants received dual antiplatelet (aspirin and clopidogrel) treatment for 12 months after enrollment. The patients also received antihyperlipidemic and antihypertensive agents according to clinical practice guidelines. Patients needing anticoagulant therapy were also excluded from the study.

Patients were distributed into three groups according to treatment regimen: group A, bypass procedure with synthetic grafts of polytetrafluoroethylene or polyester; group B, endovascular treatment of angioplasty or bare metal nitinol stenting; and group C, conservative treatment with antiplatelet drugs and statins. Peripheral venous blood samples were collected in groups A and B before and three months after operative or endovascular treatment; in group C, only baseline samples were obtained. Activities of intrinsic pathway coagulation factors VIII, IX, and $\mathrm{XI}$ were assessed using a Sysmex CA 50 analyzer (Sysmex Corporation, Kobe, Japan). Hemostatic markers of endothelial dysfunction, such as SEPCR, vWF antigen, and PAl-1, were analyzed using ELISA with a Lazurit analyzer (Dynex Technologies, Chantilly, VA, USA). The activity of vWF was evaluated using a ristocetin-induced agglutination test. Nitric oxide (NO) metabolites and nitrite levels were assessed by photocolorimetry using Griess reagent and a Stat Fax 3200 analyzer (Awareness Technology, Inc., Palm City, FL, USA) set to $540 \mathrm{~nm}$. 
Ankle-brachial index ( $\mathrm{ABI}$ ) measurement and duplex ultrasonography (DUS) of the lower extremity vessels were performed at baseline in all patients. Patients in groups $A$ and $B$ underwent angiography at baseline and upon repeat physical examination. $\mathrm{ABl}$ measurement and DUS testing were also performed at 3, 6, and 12 months after revascularization. Patients in group $C$ underwent repeat vascular testing at 12 months. Additionally, we evaluated graft patency in terms of restenosis and disease progression. Progression of the disease was defined as any increase in the degree of stenosis other than the revascularization area or any newly detected atherosclerotic lesion.

Statistical analysis was performed using StatSoft Statistica software version 13.0 (TIBCO Software Inc., Palo Alto, (A, USA) and Microsoft Excel for MAC ver. 16.24. Comparisons were made using the Mann-Whitney U-test, as a nonparametric alternative test to the independent sample ttest, Wilcoxon test for paired samples, and Spearman rank correlation for determining any associations between two ranked variables. For variables with normal distribution, Student t-distribution was used when estimating the mean of a normally distributed population. A threshold probability value of $P \leq 0.05$ was used to indicate statistical significance. Multiple logistic regression was used to assess any associations between the activity of coagulation factors and levels of hemostatic markers of endothelial dysfunction and adverse outcomes. The study was approved by the Institutional Review Board of Ryazan State Medical University (No. 01/2017). All subjects gave informed consent to the work.

\section{RESULTS}

One hundred and twenty subjects were distributed into three groups, with 40 patients each, based on the treatment methods described above. Decisions regarding the type of revascularization or conservative treatment were made by a team of vascular specialists, considering the following: severity of claudication, previous treatment, anatomy, possible need for repeat procedures in the future, and patient preferences. Patients in each group were comparable in terms of age, sex, and concomitant pathology. Patient demographics and procedure details are presented in Table 1.

The normal values of the studied parameters were as follows: vWF activity 70\%-150\%, vWF antigen 0.5-1.5 U/ $\mathrm{mL}$, factor VIII 70\%-150\%, factor VIII 70\%-150\%, factor IX 70\%-150\%, factor X1 70\%-130\%, PAl-1 7-43 ng/mL, sEPCR 2-43 ng/mL, and NO metabolites 76-80 mcM/mL.

At baseline, the activities of VWF, FVIII, FIX, and FXI, levels of PAl-1, and SEPCR were increased in group A com- pared to normal values. Compared to group $C$ patients, the activities of vWF $(\mathrm{P}=0.001)$, vWF antigen $(\mathrm{P}<0.001)$, FVIII $(P<0.001)$, FIX $(P=0.045), F X 1 \quad(P<0.001)$, NO metabolite levels $(P=0.028)$ and sEPCR levels $(P<0.001)$ were increased in group A patients; vWF antigen level was normal, but NO metabolite levels were decreased compared to normal values (Fig. 1). At 3 months after open bypass grafting, this trend remained (Table 2). FVIIl activity was significantly increased compared to the control $(\mathrm{P}<0.001)$ and the level of NO metabolites was also significantly increased compared to that in group $\mathrm{C}(\mathrm{P}=0.012)$. At three months, the strongest correlations were found between the activities of factors VIII and IX ( $r=+0.556)$, VWF and factor VIII $(r=+0.698)$, vWF and factor IX ( $r=+0.508), \mathrm{VWF}$ and factor XI ( $\mathrm{r}=+0.558)$, factor $\mathrm{VIII}$ and $\mathrm{XI}(\mathrm{r}=+0.733)$, and factors $\mathrm{IX}$ and $\mathrm{XI}(\mathrm{r}=+0.631)$. Five patients in group A were diagnosed with disease progression at 12 months according to DUS; they had increased activity of VWF, factors VIII, IX, and XI, elevated levels of SEPCR and PAl-1, and decreased levels of NO metabolites at baseline. At 3 months, they showed statistically significant increases in $\mathrm{VWF}$ activity $(\mathrm{P}=0.027)$ and $\mathrm{NO}$ metabolite levels $(P=0.014)$. Six $(15 \%)$ patients in group A with initially

Table 1 . Patient demographics and corresponding treatment methods

\begin{tabular}{|c|c|c|c|}
\hline Parameter & Group A & Group B & Group C \\
\hline Age (y) & $63.4 \pm 7.9$ & $63.9 \pm 7.9$ & $59.8 \pm 8.3$ \\
\hline Sex, male & $33(82.5)$ & $35(87.5)$ & $36(90)$ \\
\hline \multicolumn{4}{|l|}{ Fontaine stage of ischemia } \\
\hline $\mathrm{Ilb}$ & $11(27.5)$ & $13(32.5)$ & $37(85)$ \\
\hline III & $29(72.5)$ & $27(67.5)$ & $3(15)$ \\
\hline \multicolumn{4}{|l|}{ Comorbidity } \\
\hline Ischemic heart disease & $16(40)$ & $19(47.5)$ & $15(37.5)$ \\
\hline Arterial hypertension & 15 (37.5) & $17(42.5)$ & $20(50)$ \\
\hline Myocardial infarction & $9(22.5)$ & $8(20)$ & $8(20)$ \\
\hline \multicolumn{4}{|c|}{ Localization of atherosclerotic lesion } \\
\hline Aortoiliac & $13(32.5)$ & $17(42.5)$ & $13(32.5)$ \\
\hline Femoropopliteal & $27(67.5)$ & $23(57.5)$ & $27(67.5)$ \\
\hline \multicolumn{4}{|l|}{ Bypass surgery in group A } \\
\hline Aorto-bifemoral bypass & $9(22.5)$ & - & - \\
\hline Femoro-femoral bypass & $4(10)$ & - & - \\
\hline Femoro-popliteal (AK) bypass & $27(67.5)$ & - & - \\
\hline \multicolumn{4}{|l|}{ Intervention in group B } \\
\hline \multirow[t]{2}{*}{ Aortoiliac } & \multicolumn{3}{|c|}{$17(42.5)$} \\
\hline & \multicolumn{3}{|c|}{3 angioplasty, 14 stents } \\
\hline \multirow[t]{2}{*}{ Femoropopliteal } & \multicolumn{3}{|c|}{$23(57.5)$} \\
\hline & \multicolumn{3}{|c|}{20 angioplasty, 3 stents } \\
\hline
\end{tabular}

Values are presented as mean \pm standard deviation or number (\%). AK, above-knee; -, not available. 

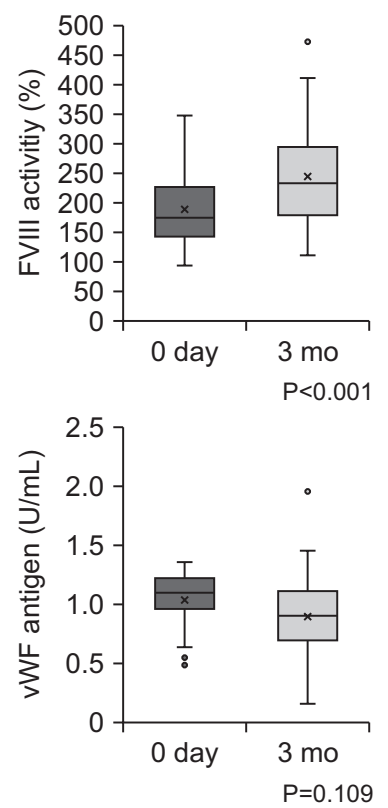
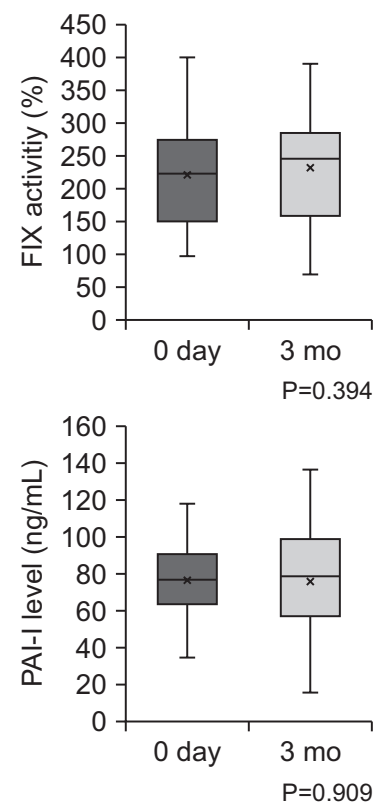
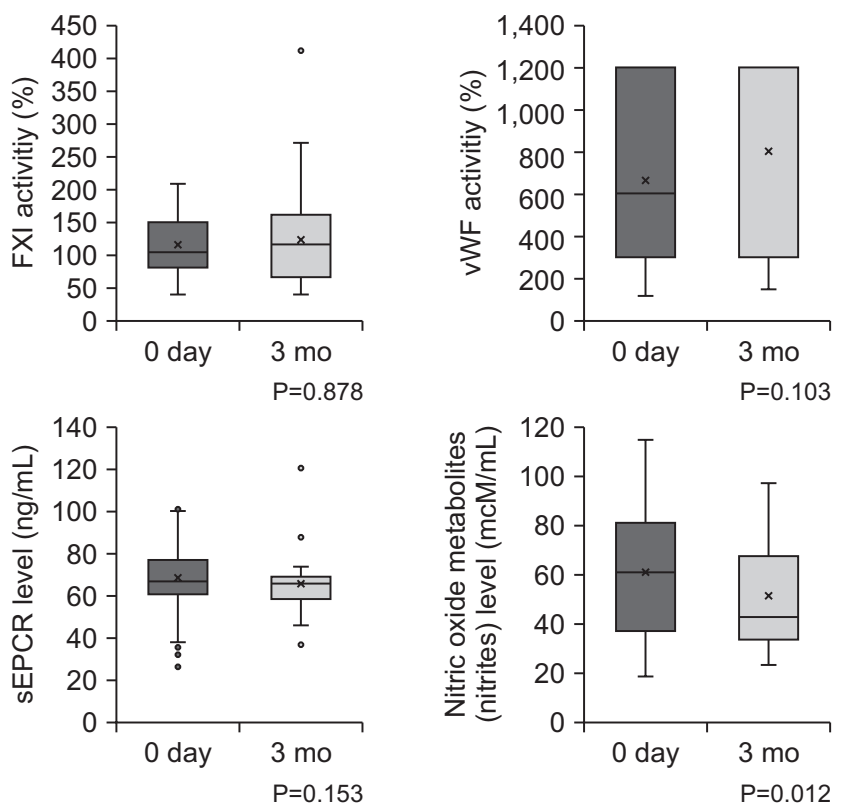

Fig. 1. Changes of coagulation factors and hemostatic markers in group A patients (open bypass grafting). vWF, von Willebrand factor; PAI-1, plasminogen activator inhibitor type 1 ; sEPCR, soluble endothelial protein $C$ receptor.

Table 2. Coagulation factors and hemostatic among the groups

\begin{tabular}{|c|c|c|c|c|c|c|c|c|}
\hline & \multirow{2}{*}{$\begin{array}{c}\text { Normal } \\
\text { value }\end{array}$} & \multicolumn{3}{|c|}{ Group A } & \multicolumn{3}{|c|}{ Group B } & \multirow{2}{*}{$\begin{array}{c}\text { Group C } \\
\text { Baseline (IOR) }\end{array}$} \\
\hline & & Baseline (IOR) & 3 months (IQR) & $P$-value ${ }^{a}$ & Baseline (IOR) & 3 months (IOR) & $P$-value ${ }^{a}$ & \\
\hline vWF activity (\%) & $70-150$ & $600(300-1200)$ & $1200(300-1200)$ & 0.103 & $600(300-1200)$ & $660(300-800)$ & 0.703 & $300(160-400)$ \\
\hline vWF antigen $(\mathrm{U} / \mathrm{mL})$ & $0.5-1.5$ & $1.1(0.96-1.2)$ & $1.0(0.78-1.16)$ & 0.109 & $0.92(0.82-1.0)$ & 0.9 (0.7-1.08) & 0.949 & $0.9(0.83-1.0)$ \\
\hline Factor VIII (\%) & $70-150$ & $175(145-226)$ & 233 (179-294) & $<0.001$ & $157(128-210)$ & $184(138-271)$ & 0.012 & $134(96.6-156.9)$ \\
\hline Factor IX (\%) & $70-150$ & $222(151-275)$ & $246(158-284)$ & 0.394 & $180(134-237)$ & $218(156-297)$ & 0.010 & $202(122-255)$ \\
\hline Factor XI (\%) & $70-130$ & $189(141-270)$ & 208 (118-287) & 0.878 & 156 (92-195) & $181(119-226)$ & 0.011 & $132(101-159)$ \\
\hline PAI-I (ng/mL) & $7-43$ & $76(65.3-90.5)$ & $78.1(56.5-98.3)$ & 0.909 & $78(47-110)$ & $97(48-119)$ & 0.909 & $77(43-133)$ \\
\hline sEPCR (ng/mL) & $2-43$ & 67 (61.2-75.3) & $65(58-68)$ & 0.153 & $57(43-87)$ & $57(44-100)$ & 0.182 & $49(39-52)$ \\
\hline $\begin{array}{l}\text { NO metabolites } \\
(\mathrm{mcM} / \mathrm{mL})\end{array}$ & $76-80$ & $60(37-81)$ & 43 (34-67.7) & 0.012 & $65(48-72)$ & $52(35-69)$ & 0.027 & $72(50-95)$ \\
\hline
\end{tabular}

IQR, interquartile range; $v W F$, von Willebrand factor; PAI-1, plasminogen activator inhibitor type 1 ; sEPCR, soluble endothelial protein $\mathrm{C}$ receptor; NO, nitric oxide.

${ }^{a}$ Wilcoxon signed-rank test.

increased activity of factor VIIl developed thrombosis in the early post-operative period leading to amputation; however, we cannot completely rule out the possibility of technical failure due to overestimation of distal runoff and technical difficulties while performing distal anastomosis.

In group B, baseline activities of VWF, factors VIII, IX, and $\mathrm{Xl}$, and levels of PAl-1 and SEPCR increased compared to normal values (Fig. 2). In group C, the activities of vWF, factor IX, and SEPCR levels increased, vWF antigen levels were normal, and NO metabolite levels decreased compared to normal values. At three months after endovascular treatment, the activities of factors VIII, IX, and XI significantly increased while PAl-1 levels significantly decreased; additionally, vWF antigen levels remained normal (Table 2). At three months after endovascular treatment, the strongest correlations were found between factors VIII and XI $(\mathrm{r}=+0.657)$, factors $\mathrm{IX}$ and $\mathrm{XI}(\mathrm{r}=+0.595), \mathrm{VWF}$ and factor VIII $(\mathrm{r}=+0.527)$, and $\mathrm{vWF}$ and NO metabolite levels $(\mathrm{r}=-0.515)$. One patient in group B with increased activity of both coagulation factors (FVIII 190\%, FIX 187\%, FXI 210\%, vWF $300 \%$ ) and hemostatic markers of endothelial dysfunction (PAl-1 $150 \mathrm{ng} / \mathrm{mL}$, sEPCR $101.9 \mathrm{ng} / \mathrm{mL}$, NO metabolites $102 \mathrm{mcM} / \mathrm{mL}$ ) in absolute values developed thrombosis at 3 months. Four (10\%) patients in group B with initially 

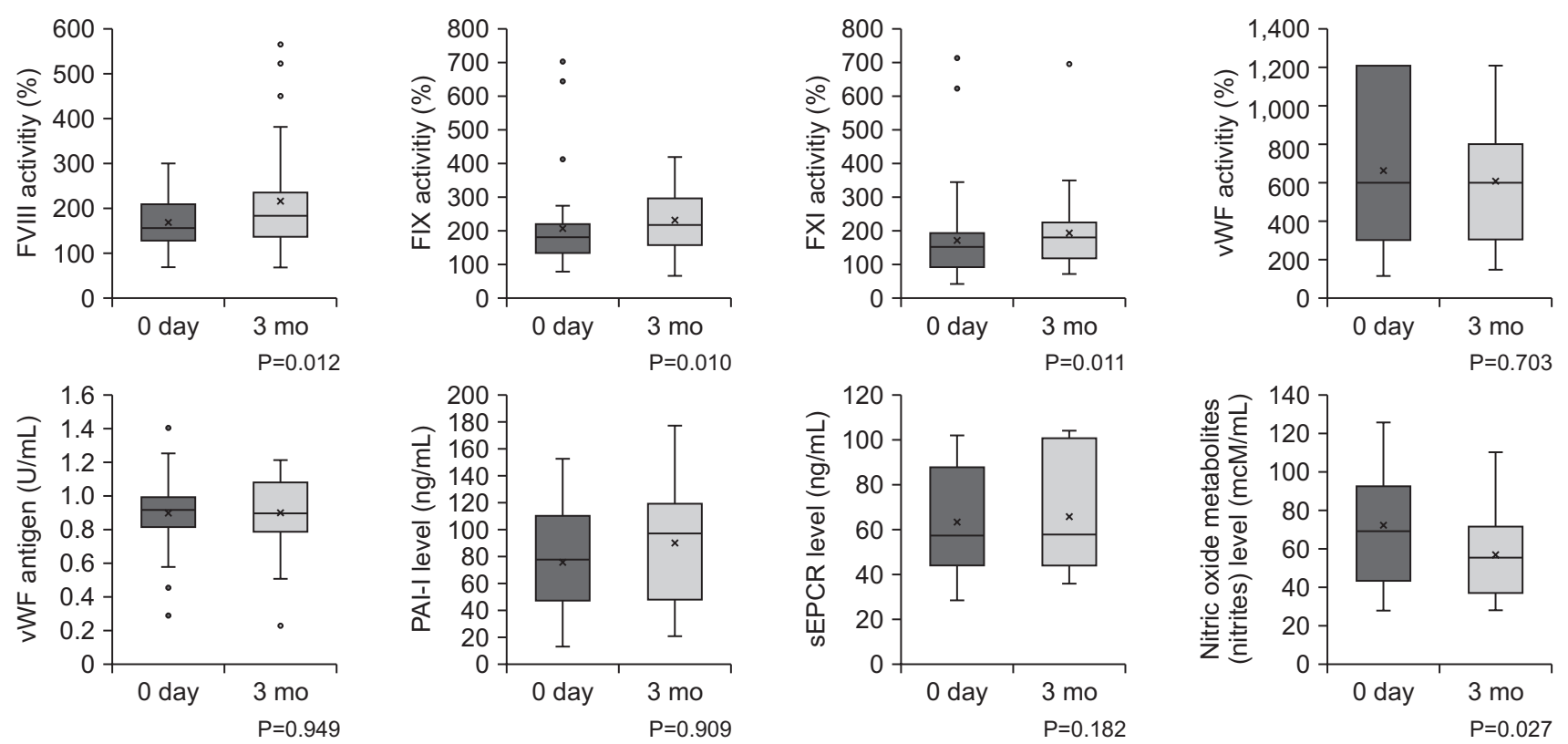

Fig. 2. Changes of coagulation factors and hemostatic markers after endovascular treatment in group B patients (endovascular treatment). vWF, von Willebrand factor; PAI-1, plasminogen activator inhibitor type 1; sEPCR, soluble endothelial protein $\mathrm{C}$ receptor.

Table 3. Logistic regression for risk factors of thrombosis in all patients included in the study

\begin{tabular}{|c|c|c|c|c|c|c|}
\hline \multirow{2}{*}{ Variable } & \multicolumn{3}{|c|}{ Univariate analysis } & \multicolumn{3}{|c|}{ Multivariate analysis } \\
\hline & P-value & $\mathrm{OR}$ & $95 \% \mathrm{Cl}$ & $\mathrm{P}$-value & $\mathrm{OR}$ & $95 \% \mathrm{Cl}$ \\
\hline Age (y) & 0.484 & 0.965 & $0.874-1.066$ & NA & NA & NA \\
\hline Sex, male & 0.827 & 0.792 & $0.099-6.348$ & NA & NA & NA \\
\hline \multicolumn{7}{|l|}{ Stage of ischemia } \\
\hline Fontaine IIb & 0.998 & NA & NA & NA & NA & NA \\
\hline Fontaine III & 0.613 & 1.771 & $0.193-16.258$ & & & \\
\hline Ischemic heart disease & 0.168 & NA & NA & NA & NA & NA \\
\hline Myocardial infarction history & 0.240 & NA & NA & NA & NA & NA \\
\hline Arterial hypertension & 0.464 & 1.836 & $0.35-9,639$ & NA & NA & NA \\
\hline vWF activity baseline & 0.179 & 1.001 & 0.999-1.003 & NA & NA & NA \\
\hline vWF antigen baseline & 0.948 & 0.873 & $0.015-51.968$ & NA & NA & NA \\
\hline Factor VIII baseline & $0.004^{*}$ & 1.021 & $1.006-1.035$ & $0.005^{*}$ & 1.025 & $1.007-1.043$ \\
\hline Factor IX baseline & 0.396 & 1.003 & $0.996-1.01$ & NA & NA & NA \\
\hline Factor XI baseline & 0.291 & 1.003 & 0.997-1.009 & NA & NA & NA \\
\hline PAI-I baseline & 0.784 & 1.003 & $0.981-1.026$ & NA & NA & NA \\
\hline sEPCR baseline & $0.029^{*}$ & 1.046 & $1.005-1.089$ & $0.027^{*}$ & 1.061 & $1.007-1.117$ \\
\hline NO metabolites baseline & 0.870 & 0.997 & $0.966-1.03$ & NA & NA & NA \\
\hline
\end{tabular}

$\mathrm{OR}$, odds ratio; $\mathrm{Cl}$, confidence interval; $\mathrm{vWF}$, von Willebrand factor; PAI-1, plasminogen activator inhibitor type 1; sEPCR, soluble endothelial protein $\mathrm{C}$ receptor; $\mathrm{NO}$, nitric oxide; $\mathrm{NA}$, not available.

${ }^{*} \mathrm{P}<0.05$.

increased $\mathrm{VWF}$ activity developed myocardial infarction during a 6-month follow-up period and underwent percutaneous coronary interventions. Six patients with restenosis initially had increased activity of vWF and decreased NO metabolite levels; at three months, vWF activity increased $(P=0.014)$ while NO metabolite levels decreased $(P=0.006)$.

Patients in group $\mathrm{C}$ had moderate activities of VWF, factors $\mathrm{IX}$, and $\mathrm{Xl}$, and average levels of PAl-1 and SEPCR. 
The levels of vWF antigen and NO metabolites were normal (Table 2). The strongest correlations were found between the activity of factors VIII and IX ( $r=+0.603)$, VIII and XI $(r=+0.609)$, and $I X$ and $X I(r=+0.603)$. Three (7.5\%) patients in group $C$ with initially increased activity of vWF developed myocardial infarction 6 months after the start of the study and underwent percutaneous coronary interventions. Three (7.5\%) patients in group C with an initially increased activity of PAl-1 developed progression of peripheral atherosclerosis at 12 months.

Multiple logistic regression performed in all patients in the study showed that elevated activity of FVIII $(\mathrm{P}=0.005)$ and levels of sEPCR $(P=0.027)$ were associated with increased risks of peripheral arterial thrombosis: the higher the activity of FVIII and levels of SEPCR, the higher the risk (Table 3).

Subgroup analysis and multiple logistic regression performed in patients who underwent endovascular treatment showed an association between the decreased levels of sEPCR $(P=0.042)$ and NO metabolites $(P=0.037)$ and increased risks of restenosis within one year after intervention: the lower the sEPCR and NO metabolite levels, the higher the risk of restenosis (Table 4).

\section{DISCUSSION}

This study showed higher activities of intrinsic coagula- tion factors and hemostatic markers of endothelial dysfunction in patients in groups A and B than in group C, which was partially explained by the higher proportion of patients in these groups with a more advanced stage of ischemia (Fontaine stage 111: group A, 72.5\%; group B, 67.5\%; group C, 15\%). Open or endovascular reconstructive procedures may promote hypercoagulability and endothelial dysfunction, which is reflected in increased activities of VWF, PAI-1, elevated levels of sEPCR, and low levels of NO metabolites at 3 months after the procedure. Our previous studies have shown that NO metabolite levels decrease in accordance with the progression of ischemia in patients with atherosclerotic PAD [14-16].

Interestingly, increased activity of VWF and low levels of NO may be predictors of restenosis and disease progression. This study showed that, at three months after open revascularization, patients in group A had decreased levels of NO metabolites while activities of VWF, factors VIII, IX, and XI increased. Three months after endovascular treatment in group B patients, there was a negative correlation observed between the activity of VWF and NO metabolite levels, which corresponds to previously reported data that NO has a negative impact on vWF secretion. Classical effects of NO are mediated via the cyclic guanosine monophosphate (cGMP) signaling pathway and cGMP dependent proteinkinase-1; its activation leads to the inhibition of agonistinduced mobilization of calcium ions and thus secretion of

Table 4. Logistic regression for risk factors of restenosis in group B patients (endovascular treatment)

\begin{tabular}{|c|c|c|c|c|c|c|}
\hline \multirow{2}{*}{ Variable } & \multicolumn{3}{|c|}{ Univariate analysis } & \multicolumn{3}{|c|}{ Multivariate analysis } \\
\hline & P-value & OR & $95 \% \mathrm{Cl}$ & P-value & OR & $95 \% \mathrm{Cl}$ \\
\hline Age (y) & 0.260 & 0.93 & $0.817-1.058$ & NA & NA & NA \\
\hline Sex, male & 0.759 & 0.735 & $0.107-5.071$ & NA & NA & NA \\
\hline \multicolumn{7}{|l|}{ Stage of ischemia } \\
\hline Fontaine IIb & 0.925 & 0.9 & $0.064-12.583$ & NA & NA & NA \\
\hline Fontaine III & 0.731 & 0.711 & $0.1-5.03$ & & & \\
\hline Ischemic heart disease & 0.434 & 1.786 & $0.415-7.693$ & NA & NA & NA \\
\hline Myocardial infarction history & 0.346 & 0.02 & $0.467-8.571$ & NA & NA & NA \\
\hline Arterial hypertension & 0.187 & 3.478 & $0.448-27.02$ & NA & NA & NA \\
\hline vWF activity baseline & 0.355 & 1.001 & 0.999-1.003 & NA & NA & NA \\
\hline vWF antigen baseline & 0.898 & 0.758 & $0.011-51.658$ & NA & NA & NA \\
\hline Factor VIII baseline & 0.123 & 0.986 & 0.967-1.005 & NA & NA & NA \\
\hline Factor IX baseline & 0.508 & 1.002 & $0.996-1.008$ & NA & NA & NA \\
\hline Factor XI baseline & 0.816 & 1.001 & 0.995-1.007 & NA & NA & NA \\
\hline PAI-I baseline & $0.026^{*}$ & 0.958 & $0.922-0.995$ & 0.389 & NA & NA \\
\hline sEPCR baseline & $0.045^{*}$ & 0.863 & $0.748-0.997$ & $0.042^{*}$ & 0.832 & $0.698-0.993$ \\
\hline NO metabolites baseline & $0.031^{*}$ & 0.938 & $0.885-0.994$ & $0.037^{*}$ & 0.918 & $0.847-0.995$ \\
\hline
\end{tabular}

$\mathrm{OR}$, odds ratio; $\mathrm{Cl}$, confidence interval; $\mathrm{vWF}$, von Willebrand factor; $\mathrm{PAI}-1$, plasminogen activator inhibitor type 1; sEPCR, soluble endothelial protein $\mathrm{C}$ receptor; $\mathrm{NO}$, nitric oxide; NA, not available.

${ }^{*} \mathrm{P}<0.05$. 
vWF [17]. We have previously shown that the lack of NO in open bypass grafting leads to excessive adhesive properties of the endothelium, monocyte migration into the subendothelial structures, platelet activation, hypercoagulation, and enhanced proliferation of smooth muscle cells [13].

The role of VWF as a predictor of the development of thrombotic complications in PAD patients, including myocardial infarction, may be explained by its biological function; it functions in the adhesion of platelets to the endothelium and protection of factor VIII from proteolysis by protein $\mathrm{C}$, which determine both platelet and fibrin components of intra-arterial thrombosis. In relation, Costa et al. [18] reported an association between factor VIII and acute myocardial infarction.

Lazarenko et al. [19] found higher levels of PAl-1 in both systemic and local blood samples in patients with atherosclerotic PAD. The possible influence of PAl-1 on the progression of the disease may be due to its role in regulating the migration of smooth muscle cells in the vascular wall. The correlation between PAI-1 and factor XI may be explained by the fact that factor $\mathrm{X}$ activates thrombin-activated fibrinolysis inhibitor (TAFI), which subsequently inhibits fibrinolytic activity; at the same time, PAl-1 inhibits plasminogen, limiting fibrinolysis. The correlation between SEPCR and PAI-l levels may be explained by the fact that SEPCR may inhibit the anticoagulant activity of protein C, which limits its neutralizing effects on PAl-1 [20].

This study had several limitations. This study did not include an assessment of the whole spectrum of coagulation cascade factors and platelet aggregation due to cost and time limitations. Second, the effect of antiplatelet or anticoagulant therapy after bypass or intervention could not be evaluated because of the study design. Third, due to the small sample size, the impact of the method of intervention or bypass could not be compared.

\section{CONCLUSION}

The activities of intrinsic coagulation factors and hemostatic markers of endothelial dysfunction were increased in patients with advanced atherosclerotic PAD. Invasive treatment, including open or endovascular procedures, promotes further hypercoagulability. Increased activity of coagulation factors and altered levels of hemostatic markers of endothelial dysfunction were associated with PAD complications such as graft thrombosis, myocardial infarction, disease progression, and restenosis.

\section{FUNDING}

The study was supported by the European Society for Vascular Surgery Research Grant (2016).

\section{CONFLICTS OF INTEREST}

The authors have nothing to disclose.

\section{ORCID}

\author{
Roman E. Kalinin \\ https://orcid.org/0000-0002-0817-9573 \\ lgor A. Suchkov \\ https://orcid.org/0000-0002-1292-5452 \\ Nina D. Mzhavanadze \\ https://orcid.org/0000-0001-5437-1112 \\ Olga N. Zhurina \\ https://orcid.org/0000-0002-2159-582X \\ Emma A. Klimentova \\ https://orcid.org/0000-0003-4855-9068 \\ Vladislav 0. Povarov \\ https://orcid.org/0000-0001-8810-9518
}

\section{AUTHOR CONTRIBUTIONS}

Concept and design: REK, IAS, NDM. Analysis and interpretation: NDM, EAK, VOP. Data collection: NDM, EAK, ONZ. Writing the article: NDM, EAK. Critical revision of the article: REK, IAS, NDM. Final approval of the article: REK, IAS, NDM. Statistical analysis: NDM, EAK, VOP. Obtained funding: REK. Overall responsibility: REK, NDM.

\section{REFERENCES}

1) Singh P, Harper $Y$, Oliphant CS, Morsy M, Skelton M, Askari R, et al. Peripheral interventions and antiplatelet therapy: role in current practice. World J Cardiol 2017;9:583-593.

2) Katsanos K, Al-Lamki SA, Parthipun A,
Spiliopoulos S, Patel SD, Paraskevopoulos 1, et al. Peripheral stent thrombosis leading to acute limb ischemia and major amputation: incidence and risk factors in the aortoiliac and femoropopliteal arteries. Cardiovasc Intervent
Radiol 2017;40:351-359.

3) Sana TR, Janatpour MJ, Sathe M, McEvoy LM, McClanahan TK. Microarray analysis of primary endothelial cells challenged with different inflammatory and immune cytokines. Cyto- 
kine 2005;29:256-269.

4) Mohan Rao LV, Esmon CT, Pendurthi UR. Endothelial cell protein $C$ receptor: a multiliganded and multifunctional receptor. Blood 2014;124:1553-1562.

5) Delvaeye M, Conway EM. Coagulation and innate immune responses: can we view them separately? Blood 2009;114:2367-2374.

6) Doolittle RF. Coagulation in vertebrates with a focus on evolution and inflammation. J Innate Immun 2011;3:9-16.

7) Sanders YV, Eikenboom J, de Wee EM, van der Bom JG, Cnossen MH, Degenaar-Dujardin ME, et al. Reduced prevalence of arterial thrombosis in von Willebrand disease. J Thromb Haemost 2013;11:845-854.

8) Zanolini D, Merlin S, Feola M, Ranaldo G, Amoruso A, Gaidano G, et al. Extrahepatic sources of factor V111 potentially contribute to the coagulation cascade correcting the bleeding phenotype of mice with hemophilia A. Haematologica 2015;100:881-892.

9) Hoffman M, Pawlinski R. Hemostasis: old system, new players, new directions. Thromb Res 2014;133 Suppl 1:S1-S2.

10) Monroe DM, Hoffman M. What does it take to make the perfect clot? Arterioscler Thromb Vasc Biol 2006;26:41-
48.

11) Kotschy D, Kotschy M, Socha P, Masłowski L, Kwapisz J, Żuk N, et al. Tissue factor and other hemostatic parameters in patients with advanced peripheral artery disease after endovascular revascularization - search for hemostatic factors which indicate restenosis. Adv Clin Exp Med 2015;24:9398.

12) Srámek A, Kriek M, Rosendaal FR. Decreased mortality of ischaemic heart disease among carriers of haemophilia. Lancet 2003;362:351-354.

13) Johansson K, Jansson JH, Johansson L, Bylesjö 1, Nilsson TK, Eliasson $\mathrm{M}$, et al. Factor XIl as a risk marker for hemorrhagic stroke: a prospective cohort study. Cerebrovasc Dis Extra 2017;7:84-94.

14) Kalinin RE, Suchkov IA, Pshennikov AS. [Correction of endothelial dysfunction as a component in treatment for atherosclerosis obliterans of lower-limb arteries]. Angiol Sosud Khir 2014;20:1722. Russian.

15) Kalinin RE, Suchkov IA, Nikiforov AA, Phennikov AS. Dynamics of some biochemical parameters in patients with peripheral occlusive arterial disease at different periods following reconstructive surgery. I.P. Pavlov Rus Med
Biol Her 2012;20:41-44.

16) Kalinin RE, Suchkov IA, Pshennikov AS, Slepnev AA. [L-arginine efficiency in treatment for lower limbs arteries atherosclerosis and in prevention of reconstruction zone restenosis]. Bull lvanovo Med Acad 2013;18:18-21. Russian.

17) Vischer UM. von Willebrand factor, endothelial dysfunction, and cardiovascular disease. J Thromb Haemost 2006;4:1186-1193.

18) Costa C, Alves M, Durão D, Leal M, Monteiro 1. Elevated factor V111 in a patient with acute coronary syndrome. Rev Port Cardiol 2014;33:181. e1-181.e4.

19) Lazarenko VA, Bobrovkaya EA, Khruslov MV, Yukhanoval YU. [Assessment of fibrinolytic activity in patients with peripheral arterial disease before and after reconstructive procedures]. Thromb Hemost Rheol 2017;69:55-59. Russian.

20) Zhalyalov AS, Balandina AN, Kuprash AD, Srivastava A, Shibeko AM. The overview of fibrinolysis system contemporary concepts and of its disorders diagnostic methods. Pediatr Hematol Oncol Immunopathol 2017;16:69-82. 